\title{
Interpretation of Non-Exhaust Brake Emission Standard: Laboratory Testing
}

\author{
Xinfeng ZHANG ${ }^{1}$, Cheng TIAN, Zhihui NIU and Xudong LI \\ Department of Chassis Testing and Research, CATARC Automotive Test Center (Tianjin) \\ Co., Ltd. Tianjin, China
}

\begin{abstract}
Now there are more and more new energy vehicles on the road, compare to the traditional vehicles that use the oil to offer the power, the new energy vehicles use electric or hydrogen to offer the power, which have no exhaust pollution emission, but also have non-exhaust emission. Brake and tyre system are the special components of vehicles due to the frequent replacement, they are the main source of the non-exhaust emission. Brake system is one of the most important safety systems of vehicles. The system can reduce the speed of the vehicle and keep the vehicle stable when going downhill. Friction between brake disc and pads or shoes during driving creates small particles that are released into the atmosphere, soil and rivers. The particles have different dimensions, some element or matter inside maybe harmful to human and environment. So it is very important to know more about the non-exhaust brake emission. Here, we focus on the specification of GRPE-81-12 "Non-Exhaust Brake Emissions - Laboratory testing - Part 1: Inertia Dynamometer Protocol to Measure and Characterise Brake Emissions Using the WLTP-Brake Cycle" and do the detailed interpretation.
\end{abstract}

Keywords. New energy vehicles, brake system, pollution emission

\section{Introduction}

International interest in the emission characteristics of non-exhaust traffic-related particulates has increased dramatically. Until recently, road traffic emissions were dominated by tailpipe emissions, and all regulatory requirements focused on reducing emissions. With the reduction of exhaust emissions, non-exhaust emissions' relative contribution to the overall environmental PM concentration increases [1]. According to studies, non-exhaust emissions such as tire wear, brake wear and road dust can account for $50 \%$ of PM in the air under certain conditions [2, 3].

Specification (GRPE-81-12, conference document) was established by the United Nations WP29 GRPE PMP (Particle Measurement Procedure) IWG (Informal Working Group). The IWG's work focuses on WLTP brake cycle development and the measurement of brake emissions in the level of the dynamometer. This paper introduces the background of this specification, the requirements of inertial dynamometer system, the adjustment of cooling airflow velocity, test sequence and test report requirements.

The specification is the part 1 of the brake emission standard. The part 1 includes the measurement procedure, more details about WLTP brake cycle and indoor test

${ }^{1}$ Corresponding Author, Xinfeng ZHANG, Department of Chassis Testing and Research, CATARC Automotive Test Center (Tianjin) Co., Ltd. Tianjin, China; Email: xinfengzhang2008@163.com. 
method. There are two other sections that focus on sampling, measurement, and requirements for test results. The collective work, done by several PMP IWG, is quite helpful for the brake test input cycles. The brake inertial dynamometer test bench is a normal bench in the test lab around the world. The results have better repeatability and reproducibility.

This part of the brake emission standard describes much requirements about the WLTP brake cycle. These information will help us to use the cycle to test the brake emission particles. The main contents of part 1 of this emission standard are as follows:

- References, definitions, and terms of the WLTP brake cycle, sampling and measurement of brake wear particle emission;

- General requirements and performance of inertial dynamometers, and test parameters;

- WLTP brake cycle's requirements refer to the test;

- Report requirements for dynamometer test results. Now this section has not yet been finalized.

\section{Requirements of Inertia Dynamometer Test Bench}

This section introduces the requirements of the test bench. Only with the requirements, the lab can measure brake emissions using the inertial dynamometer system.

\subsection{Minimum Requirements for Data Collection}

The fast channel of braking control and output that need continuous automatic acquisition includes braking torque, braking pressure, braking equivalent linear velocity, and braking fluid displacement. The acquisition frequency is $\geq 250 \mathrm{~Hz}$ in braking deceleration process and $\geq 10 \mathrm{~Hz}$ in other braking process (stay, acceleration, cruise, etc.). There are also several slow braking and cooling air control channels and outputs that require continuous collection and automatic sampling rates of $\geq 10 \mathrm{~Hz}$, refer to the temperature of brake disc or brake drum, brake pad or brake shoe, cooling air, humidity of cooling air, speed or flow of cooling air.

\subsection{Braking Temperature Measurement}

A thermocouple is placed in the regulated place. For brake disc or brake drum, they have specific requirements for the thermocouple according to some specification. On the ventilated disc, the thermocouple is positioned between the two fins of the disc plate. In the test, the temperature will be get from the thermocouple sensors.

\subsection{Wear Measurements}

For wear measurement, the specification has no specific regulation. So we can get the information from other standard. This section is an improvement from the SAE J2986:2019 [4]. In order to conduct the test, we need to know more information about the test. It is a good choice to get them from the corresponding SAE reference.

When measuring thickness, diameter or weight, the test engineer should use equipment with an accuracy of $0.01 \mathrm{~mm} / 0.01 \mathrm{~g}$ or above. For brake pads and brake pads, 
measurements are made at eight equally spaced locations. For brake discs, measurements were made in 8 positions, in groups of 2 , each $90^{\circ}$ distributed. But for the brake drum, measurements were made in 6 positions, three sets of two, distributed every $120^{\circ}$.

\subsection{Cooling Air Conditioning}

We should keep the test average temperature to be $(20 \pm 2){ }^{\circ} \mathrm{C}$. Then we can adjust the average temperature to be $(20 \pm 5){ }^{\circ} \mathrm{C}$ in the test considering the actual conditions. We should control the test average relative humidity to be $(50 \pm 5) \%$, which is get from the sensors outside the brake cabinet. During the adjustment of the cooling airflow speed, we can adjust the average humidity to be $(50 \pm 10) \%$ in the test process.

\subsection{Speed Tolerance Limitation in the WLTP Brake Cycle}

For speed limitation, it is adapted from GTR 15 [5]. During the whole brake process, or during the cooling airflow speed adjustment, the biggest speed tolerance is $10 \%$. The speed high/low tolerance is $2.0 \mathrm{~km} / \mathrm{h}$ higher/lower than the highest/lowest point of the specified limitation within a given time point \pm 1.0 seconds.

Figure 1 is the upper and lower tolerance limits.

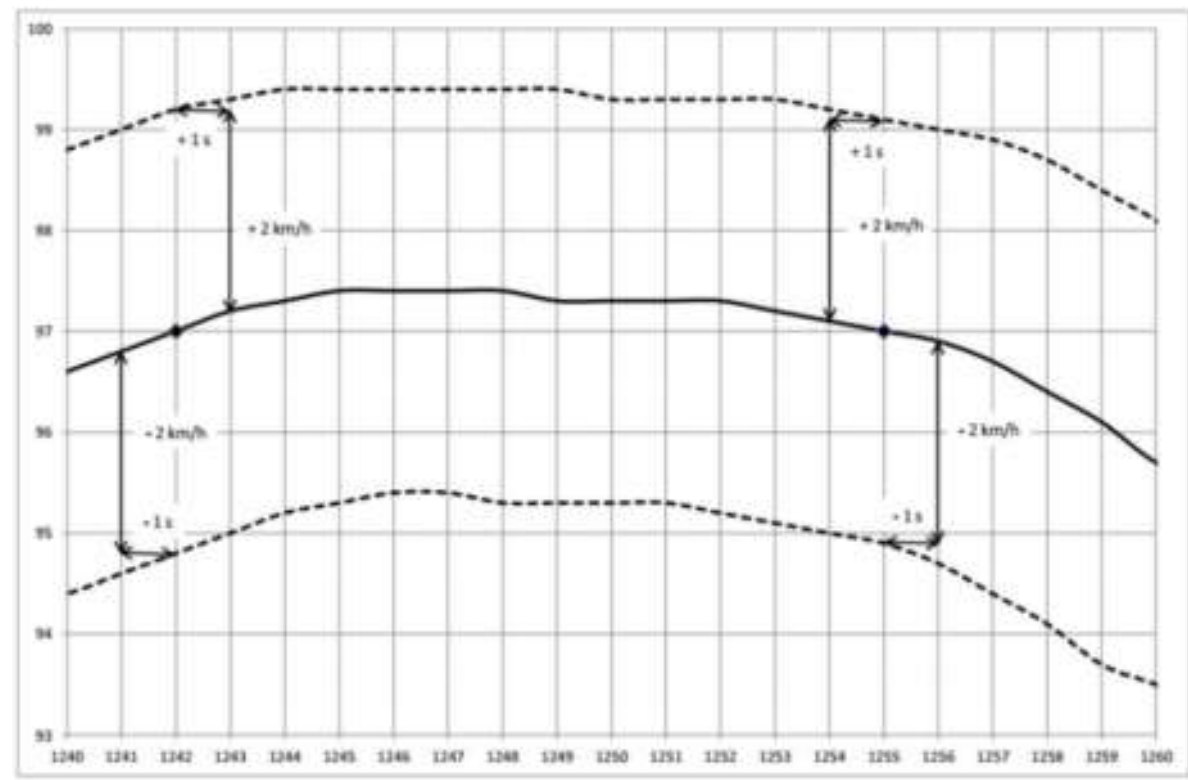

Figure 1. Tolerance limits during WLTP brake cycle.

During the test process, the speed errors, such as RMSSE, is an improved version from SAE J2951:2014 [6]. RMSSE was calculated in $\mathrm{km} / \mathrm{h}$ using the following formula 1 .

The RMSSE value should not exceed $1.6 \mathrm{~km} / \mathrm{h}$. The value equates to a $50 \%$ speed error. If the value meet $1.6 \mathrm{~km} / \mathrm{h}<$ value $<3.2 \mathrm{~km} / \mathrm{h}$, the test engineer should record the 
relevant information on the report. If RMSSE value $>3.2 \mathrm{~km} / \mathrm{h}$, we can consider that the test is failure, find and analysis the reason, and record all the information.

The sum of the squares root of the difference between the real velocity and the specified velocity, then calculate the value according to the following equation:

$$
\operatorname{RMSSE}=3.6 \times\left(\frac{\sum_{i=1}^{N}\left(v_{D i}-v_{T i}\right)^{2}}{N}\right)^{1 / 2}
$$

$v_{D i}$ : Equivalent linear velocity of the service brake at $i$ during the test cycle;

$v_{T i}$ : Target linear velocity of the service brake at time $i$ when executing the test cycle.

\subsection{Vehicle Test Mass}

Set the test mass (Driving Cycle Vehicle Mass: $D C V M$ ) to be equal to the Unladen Vehicle Mass $(U V M)$ plus additional weight according to equation (2).

$$
D C V M=U V M+1.5 \times 75
$$

\subsection{Test Inertia}

Follow any of the following options to determine test inertia in descending order of priority. Record the actual method used on the test report.

A. Braking force distribution (inertial division) specified by the manufacturer shall be adopted for the axle to be tested, and shall be confirmed by the test requester;

B. For deceleration below $0.65 \mathrm{~g}$, brake force allocation (inertial division) using the default method of SAE J2789 [7].

\subsection{Parasitic Vehicle Losses Correction}

In order to reflect the parasitic loss of vehicles, we can use any of the following method to correct it.

Torque correction based on the average parasitic loss of vehicles:

A. Using parameters F0, F1 and F2 (A, B, C), plus initial velocity, final velocity and $D C V M$ value, calculate average deceleration according to vehicle parasitic loss, equation (3).

$$
d_{\text {parasitic }}=\frac{f_{0} \cdot\left(v_{i}-v_{f}\right)+f_{1} \cdot \frac{\left(v_{i}^{2}-v_{f}^{2}\right)}{2}+f_{2} \cdot \frac{\left(v_{i}^{2}-v_{f}^{2}\right)}{3}}{D C V M \cdot\left(v_{i}-v_{f}\right)}
$$

$v_{i}$ : Initial speed of braking deceleration event;

$v_{f}$ : Final speed of braking deceleration event; 
$f_{0}$ : Fixed road load factor, rounded to one decimal point in accordance with paragraph 7 of United Nations GTR 15;

$f_{1}$ : The first-order road load factor is rounded to three decimal places according to paragraph 7 of United Nations GTR 15;

$f_{2}$ : Second-order road load factors are rounded to five decimal places according to paragraph 7 of United Nations GTR 15.

B. Subtracting the average deceleration set value of the event from the value shown in equation (3), the actual torque demand of the brake can be determined;

C. The resulting deceleration is used to calculate the corrected torque as the torque setting (demand) for the braking.

Inertia correction:

For the brake inertial dynamometer which can't be modified by the above method, the test inertia of the whole test is reduced by $13 \%$.

\subsection{Test Set up and Brake Clamp}

Before starting the actual test of airflow velocity adjustment or measuring brake emissions, perform the following tasks.

- Verify all test files, special instructions, control procedures, dynamometers and filter media capabilities of the project and availability of test conditions;

- Connect the brake assembly to the test bench and the tail seat of the dynamometer, and connect the adapter to the shaft of the main dynamometer;

- Install brake pads or brake pads, exhaust thoroughly, remove bubbles in brake pad pipeline;

- Check LRO, operating clearance and any residual brake resistance;

- Check brake device, brake fixture, sensors and relevant lines;

- Close the brake housing, turn on the conditioning system;

- Adjust the airflow of the axle under test and the maintenance brake type to confirm that the background emission level is within the acceptable range;

- Perform stop checks to verify all the sensors, all the data, all the parameters, etc.;

- If there are no problems, prepare to do the real test.

\section{Adjust the Speed of the Cooling Air Flow}

\subsection{Introduction}

Cooling air is very important for the test, the system should control airflow velocity, temperature and relative humidity. This part of the PMP brake standard establishes an appropriate method to adjust airflow velocity to provide a similar thermal regime across facilities. The only brake deceleration items to determine the mean IBT and mean FBT are \#46, \#101, \#102, \#103, \#104 and \#106 of trip 10 in the WLTP-Brake cycle. When considering the entire period, the corresponding events are \#235, \#290, \#291, \#292, \#293, and \#295 [8]. 


\subsection{Calculation of Braking Temperature and Acceptance Limit}

In order to do the test strictly, we need to set properly airflow velocity in the process. Usually, we do many times of the whole procedure to get the parameters (in table 1), then analysis the values in the two tables.

(1) Compute the values according to the vehicle data, the default values can also be used:

Values from table 2:

- Average Braking Temperature (A1)

- Average IBT (A2)

- Average FBT (A3)

- Maximum braking temperature (A4)

(2) Compute the values according to dynamometer data:

- Average Braking Temperature (B1)

- Average IBT (B2) from a single value (Y1.. 6)

- Average FBT (B3) from individual values (Z1.. 6)

- Maximum braking temperature (B4)

Table 1. Brake temperature limits in the whole process.

\begin{tabular}{|c|c|c|c|c|c|}
\hline Event [\#] & Metric & $\begin{array}{l}\text { Column A } \\
\text { Vehicle/Target }\left({ }^{\circ} \mathrm{C}\right) \\
\end{array}$ & $\begin{array}{l}\text { Column B } \\
\text { Dynamometer }\left({ }^{\circ} \mathrm{C}\right)\end{array}$ & $\begin{array}{l}\text { Column C } \\
\text { Difference }\left({ }^{\circ} \mathrm{C}\right)\end{array}$ & $\begin{array}{l}\text { Column D } \\
\text { Acceptance }\left({ }^{\circ} \mathrm{C}\right) \\
\end{array}$ \\
\hline- & \multirow[t]{7}{*}{$\begin{array}{l}\text { Average brake } \\
\text { temperature }\end{array}$} & \multirow[t]{7}{*}{ A1 } & $\mathrm{B} 1$ & $\mathrm{C} 1=|\mathrm{A} 1-\mathrm{B} 1|$ & $\mathrm{C} 1 \leq 10$ \\
\hline 46 & & & Y1 & / & I \\
\hline 101 & & & $\mathrm{Y} 2$ & / & / \\
\hline 102 & & & Y3 & / & / \\
\hline 103 & & & Y4 & / & / \\
\hline 104 & & & Y5 & / & I \\
\hline 106 & & & Y6 & / & / \\
\hline- & \multirow[t]{7}{*}{ Average IBT } & \multirow[t]{7}{*}{ A2 } & $\mathrm{B} 2=\mathrm{AVG}(\mathrm{Y} 1: \mathrm{Y} 6)$ & $\mathrm{C} 2=|\mathrm{A} 2-\mathrm{B} 2|$ & $\mathrm{C} 2 \leq 15$ \\
\hline 46 & & & $\mathrm{Z} 1$ & / $12-2.1$ & 1 \\
\hline 101 & & & $\mathrm{Z} 2$ & / & l \\
\hline 102 & & & $\mathrm{Z3}$ & / & / \\
\hline 103 & & & $\mathrm{Z4}$ & / & l \\
\hline 104 & & & $\mathrm{Z} 5$ & / & / \\
\hline 106 & & & $\mathrm{Z} 6$ & / & / \\
\hline- & \multirow{2}{*}{$\begin{array}{l}\text { Average FBT } \\
\text { Maximum brake } \\
\text { temperature }\end{array}$} & $\mathrm{A} 3$ & $\mathrm{~B} 3=\mathrm{AVG}(\mathrm{Z1}: \mathrm{Z6})$ & $\mathrm{C} 3=|\mathrm{A} 3-\mathrm{B} 3|$ & $\mathrm{C} 3 \leq 25$ \\
\hline - & & A4 & B4 & $\mathrm{C} 4=|\mathrm{A} 4-\mathrm{B} 4|$ & $\mathrm{C} 4 \leq 25$ \\
\hline
\end{tabular}

Table 2. Brake temperature limits.

\begin{tabular}{|c|c|c|c|c|c|c|c|c|}
\hline Axle & Brake type & $\begin{array}{l}\text { Ave } \\
\text { tem }\end{array}$ & $\begin{array}{l}\text { orake } \\
\text { ure }\left({ }^{\circ} \mathrm{C}\right)\end{array}$ & Ave & IBT $\left({ }^{\circ} \mathrm{C}\right)$ & Average & FBT $\left({ }^{\circ} \mathrm{C}\right)$ & $\begin{array}{l}\text { Maximum brake } \\
\text { temperature }\left({ }^{\circ} \mathrm{C}\right)\end{array}$ \\
\hline Front & Disc vented & \multirow{4}{*}{$\mathrm{A} 1$} & 85 & \multirow{4}{*}{$\mathrm{A} 2$} & 85 & & 135 & \multirow{4}{*}{ 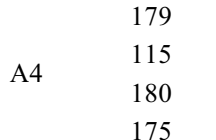 } \\
\hline Rear & Disc vented & & 65 & & 65 & \multirow{3}{*}{$\mathrm{A} 3$} & 95 & \\
\hline Rear & Disc solid & & 80 & & 85 & & 135 & \\
\hline Rear & Drum & & 60 & & 65 & & 120 & \\
\hline \multicolumn{2}{|c|}{ Acceptance } & \pm 10 & & \pm 15 & & \pm 25 & & \pm 25 \\
\hline
\end{tabular}

(3) Compute the difference between vehicle/target and dynamometer results for the following parameters:

- Absolute difference $(\mathrm{C} 1)$ in average brake temperature between A1 and B1 
- Absolute difference (C2) in average IBT between A2 and B2

- Absolute difference (C3) in average FBT between A3 and B3

- Absolute difference (C4) in maximum brake temperature between A4 and B4

D. Compare the results of step $\mathrm{C}$ with the acceptance limits for column $\mathrm{D}$ in table 1 (also included in the last row of table 2).

\subsection{Measurement for Traditional Vehicle}

Normally, the engineer drives the vehicle on the PG according to the whole brake procedure to get a balance thermal state. When we have no PG data, we use the data from the table 1. Data A1 A4 are the labels in table 2.

\subsection{Measurement for Hybrid or Electric Vehicles}

Now we have no research on brake emission for regenerative brake system. It is obviously different with traditional brake system. So, the test method for regenerative brake system will be developed in the future.

\subsection{Brake Dynamometer Test to Adjust Airflow Speed}

For a brake configuration, first test a given dynamometer when adjusting airflow speed by following the following steps. After completion of the process, follow-up tests were carried out at the same airflow velocity under repetitive parameters.

(1) Do the preparation according to clause 2.9 before starting the test;

(2) On the basis of previous test experience, set the airflow speed to a specific value. In no previous history or useful reference, a full scale dynamometer cooling system with airflow speed between $20 \%$ and $25 \%$ is used;

(3) 5 WLTP brake cycles are used to do the break-in work for the test bench and samples when applying new components (Brake discs and pads);

(4) the test using the whole WLTP brake cycle at $40^{\circ} \mathrm{C}$ IBT is done;

(5) results and deviations using clause 3.2, including assessments as defined in Clauses 2.5 and 2.8 are calculated and assessed;

(6) the process if the test meets the values in table 2 is completed;

(7) a new airflow according to the experience if the test does not meet the values in table 2 is set;

(8) further changes or adjustments are defined if there is no suitable airflow velocity combination to meet all the indicators in table 2 .

\section{Test Sequence}

\subsection{Overview}

The WLTP brake cycle has a high requirements when doing the test, especially for the speed parameters, the speed's tolerance should in the scope of the limits in clause 2.5 (figure 2).

According to the analysis, the WLTP brake cycle [9] has many key points:

- Total time is 15826 seconds; 
- Total brake event times is 1084 times;

- Total brake deceleration times is 303, 10 individual trips;

- The total cycle distance is $192 \mathrm{~km}$;

- Average braking speed is $42 \mathrm{~km} / \mathrm{h}$, maximum $132 \mathrm{~km} / \mathrm{h}$;

- Average deceleration is $0.9 \mathrm{~m} / \mathrm{s}^{2}$, maximum $2.2 \mathrm{~m} / \mathrm{s}^{2}$.

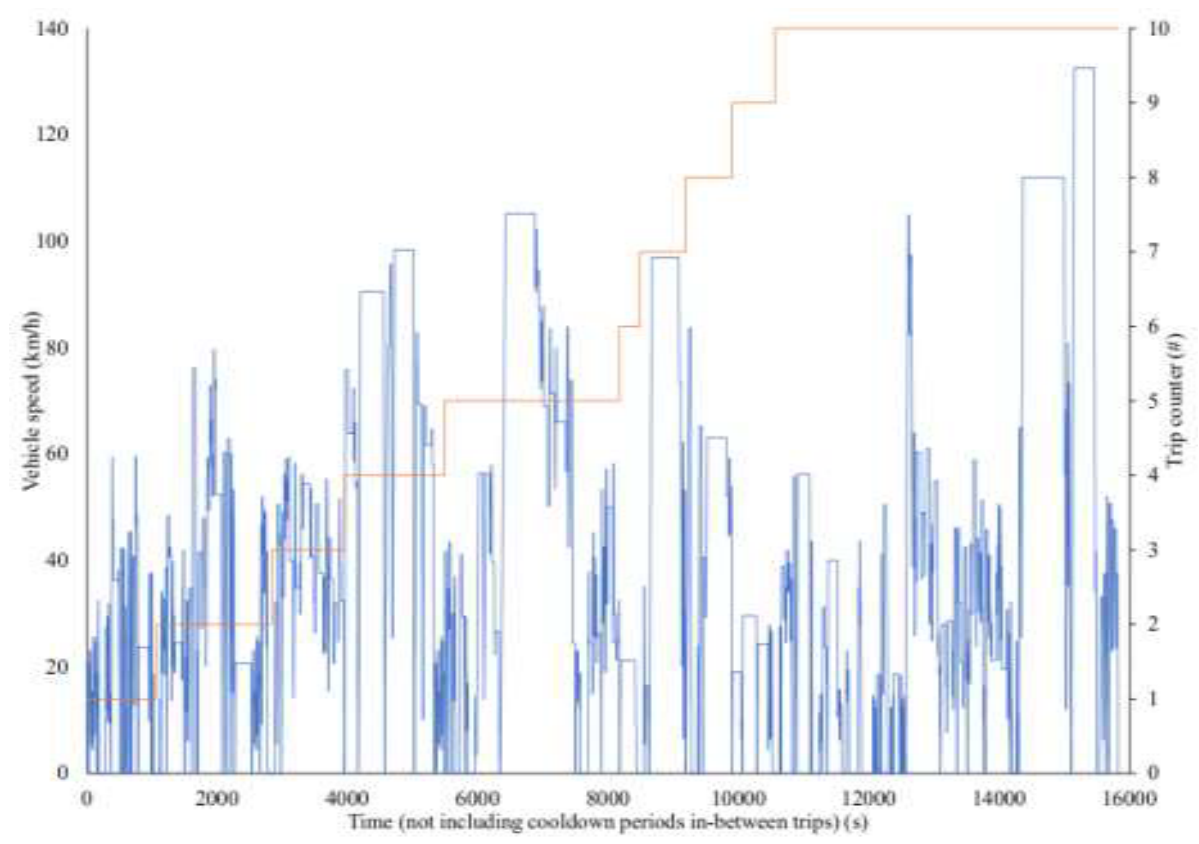

Figure 2. The WLTP brake cycle speed.

\subsection{General Consideration for Performing Standard Brake Test}

- Confirm with test requestors prior to testing and record decisions on optional items and special instructions accordingly;

- Performance of 10 consecutive trips per cycle (or repetition) of a WLTP-Brake;

- For the first repeat of the cycle, start tripping 1 at normal temperature, no any preheating stop or buffering;

- All subsequent trips, including additional cycle trip 1, wait for brake to reach $40^{\circ} \mathrm{C}$ IBT;

- Carry out 5 WLTP brake cycles as a test cushion (grinding) plan unless otherwise directed by the test requester;

- Before formal testing, talk the detail test steps;

- If the test to be failure in the process, evaluate the reason, adjust the procedure to continue the test;

- Always report any inconsistencies related to the application (use) of this test procedure. 


\subsection{Detailed Measurement for the Entire WLTP Brake Cycle and Each Trip}

It is essential to be familiar with the WLTP brake cycle, and understanding the main parameters that describe the whole cycle and each trip. These measurements are as follows:

- Time measurement for each activity;

- Lowest, average, 95th percentile and highest speed indicators;

- Count of brake stop and buffering events or percentage of the total deceleration events;

- Deceleration event count and percentage of the speed box;

- Minimum, average, 95th percentile and maximum deceleration indexes;

- Minimum, average, 95th percentile, and maximum stop/snub duration indicators;

- The total distance of each trip or the whole cycle.

\subsection{Test Procedure of Brake Deceleration Events}

There is a table in the brake emission specification that records the sequence of all brake events. The value in the table describes the stroke number mark, the whole cycle braking deceleration event number mark and the corresponding stroke, the time stamp of the start time of each event, and the braking parameters corresponding to the event duration, braking and final speed. And total deceleration level (including vehicle parasitic loss).

\section{The Test Report}

The test report is the final summary for all the information of the test. Here, we offer two different test report type, EEC and EED. For one integrated report, the format is important, but the content is more important. It at least includes the following information:

- Test basic information, include test requestor, test location, test bench and calibration information, test time, test engineer, test samples and number, test tools, standard matter and calibration information during the whole test;

- Test parameters, the test's requirements and actual parameters, include the test bench and sampling system;

- Samples information, include the brake system, the brake components, the vehicle information, and so on;

- Key data monitor and record, the brake wear measurements, the brake weight, the brake temperature, and so on;

- All pictures of test components;

- Laboratory personnel record comments and comments on any unique aspects, observations, or deviations in the testing process.

\subsection{EEC Files}

When required, CSV or MS Excel ${ }^{\mathrm{TM}}$ files were generated from the whole test data using the VDA 305 [10] standard. 


\subsection{EED Files}

When required, CSV or MS Excel ${ }^{\mathrm{TM}}$ files were generated from the whole test data using the VDA 305 standard. The data collection frequency is $1 \mathrm{~Hz}$. Much information should be included: trip number, time stamp, set value and brake speed limit, etc.

\section{Summary and Prospect}

This paper gives the main requirements of the GRPE-81-12 specification, more details can be found in the original specification file. It is just a interpretation from a purely technical view and does not involve copyright issues. The specification was submitted to the United Nations WP29 GRPE for the main purpose of providing information, not the final version. So the contents will be updated in the future, also include the other two parts of the brake emission specification.

\section{References}

[1] 2020 Non-Exhaust Brake Emissions-Laboratory testing-Part 1: Inertia Dynamometer Protocol to Measure and Characterise Brake Emissions Using the WLTP-Brake Cycle Geneva (UN WP29 81st GRPE) GRPE-81-12.

[2] Zhang X F, Chen P and Liu F Y 2020 Review of tires wear particles emission research status IOP Conference Series: Earth and Environmental Science 442-448.

[3] Zhang J and Zhang X 2018 Occurrence of benzothiazole and its derivates in tire wear, road dust, and roadside soil Chemosphere (201) 310-317.

[4] 2019 Brake Pads, Lining, Disc, and Drum Wear Measurements (United States: SAE International) SAE $\mathrm{J} 2986$.

[5] 2014 Global Technical Regulation Worldwide Harmonized Light Vehicle Test Procedure (Geneva: UN WP.29) GTR 15.

[6] 2014 Drive Quality Evaluation for Chassis Dynamometer Testing (United States: SAE International) SAE J2951.

[7] 2010 Inertia Calculation for Single-Ended Inertia-Dynamometer Testing (United States: SAE International) SAE J2789.

[8] Marcel M, Jaroslaw G, Christian S, Rainer V, Ferdinand F H, Tomasz G, Heinz S and Theodoros G 2018 A novel real-world braking cycle for studying brake wear particle emissions Wear 414 (2018a) 219-226.

[9] Marcel M, Jaroslaw G, Christian S, Rainer V, Ferdinand F H, Tomasz G, Heinz S and Theodoros G WLTP-Based real-world brake wear cycle DOI: 10.17632/dkp376g3m8.1.

[10] 2013 Recommendation for Integration of Electric Parking Brakes Control into ESC Control Units (Germany: DE-VDA) VDA 305-100. 